\title{
Assessment of Health Risk due to Pesticide Residues in Fruits, Vegetables, Soil, and Water
}

\author{
Nikhat Khan, Ghazala Yaqub (D), Tahreem Hafeez, and Madiha Tariq \\ Department of Environmental Sciences, Kinnaird College for Women, Lahore 54000, Pakistan \\ Correspondence should be addressed to Ghazala Yaqub; ghazala_yaqub@yahoo.com
}

Received 10 January 2020; Revised 10 April 2020; Accepted 12 May 2020; Published 24 June 2020

Guest Editor: Yifeng Zhang

Copyright (C) 2020 Nikhat Khan et al. This is an open access article distributed under the Creative Commons Attribution License, which permits unrestricted use, distribution, and reproduction in any medium, provided the original work is properly cited.

\begin{abstract}
The present study was conducted to assess the contamination and health risk due to the presence of pesticides in fruits and vegetables. A total of six vegetable samples, 3 fruit samples, 7 soil samples, and 6 water samples were collected from three different sampling points. High-performance liquid chromatography using acetonitrile and water solvent system was employed for the quantitative and qualitative analysis. The pesticides having the highest health risk in vegetables were Bifenthrin and Difenoconazole as their health risk index was found to be exceeding the cut off value of 1 . Imidacloprid was found in all vegetable samples but had no associated health risk, as all the health risk indices for imidacloprid were below the cut off value of 1 . The pesticide Glyphosate detected in only one sample had no health risk associated with it. Health risks in fruits were the highest for Amamectin, Bifenthrin, and Difenoconazole and were crossing the threshold limit of 1 . The results reveal the health risk indices of Bifenthrin and Difenoconazole range from 7.8 to 12.46 in vegetables and from 2.704 to 30.454 in fruits, hence, posing a serious threat to human health. Amamectin, although detected in only fruit and water samples, had the highest health risk of 30.454 . Imidacloprid and Glyphosate found in every fruit sample had no associated health risk. The results revealed the presence of pesticides in water, soil, fruit, and vegetable samples. Consumers utilizing these vegetables and fruits are under potential health risks due to the presence of pesticides in soil and water. Practical Applications. In this study, an analytical method for detecting pesticides in a variety of environmental matrices including fruits, vegetables, water, and the soil is presented and the health risk associated with the presence of pesticides in a wide range of fruits and vegetables is assessed. It is highly significant because in developing countries agricultural activities contribute majorly toward the total gross domestic product and pesticides are extensively used to control, prevent, devastate, and diminish any harmful pest that destroys crops.
\end{abstract}

\section{Introduction}

Economic growth and development is largely dependent upon agriculture. It is the main source of living and income in rural areas and it also ensures the availability of food in rural and urban populations. Being the dominant sector of the economy in Pakistan, its GDP contribution in Pakistan for the year 2019 is $18.53 \%$ [1]. Agrochemicals are intensively used globally. Developing countries have been using 108 kinds of insecticides, 30 kinds of fungicides, 39 kinds of weedicides, 5 kinds of acaricides, and 6 different kinds of rodenticides [2]. Food is the main route of exposure through which pesticide contamination can be caused. Exposure to pesticides through consumption of food is considered to be five times higher in magnitude as compared to other exposures like air and water [3]. According to the World Health Organization, fruits and vegetables are the most commonly consumed food group, and on average, $30 \%$ of food consumption is based on fruits and vegetables. Moreover, because fruit and vegetables are primarily consumed raw or semiprocessed, it is expected that they contain higher amounts of pesticide residue levels in comparison to other food groups of plant origin, such as bread and other foodstuffs based on cereal processing [4].

Pesticides due to their persistent nature, toxic properties, bioaccumulation, lipophilicity, and adverse impacts on human health are of greater concern. These pesticides can enter the human body through the consumption of contaminated fruits and vegetables. The major health impacts associated with pesticides include cancers, birth defects, 
neurological disorders, endocrine disruptors, and reproductive effects. The effect of a pesticide is determined by the duration of exposure and toxicity of a particular pesticide. The effects which can be caused are either acute or chronic. Acute effects can result in rashes, diarrhea, dizziness, rashes, and blindness. Chronic health impacts include cancers, reproductive effects, thyroid, and endocrine disruption [5]. Due to the potential health risks associated with pesticide consumption, continuous monitoring of fruits and vegetables is required. After their use on vegetables and fruits, there is no proper preharvest time frame followed because of their high market demand and less knowledge about toxic effects of pesticides which can be caused on human health after the consumption of these contaminated foods.

The residual level of pesticides is examined through the maximum residual limit which is based on the analysis of pesticide residues left behind on the food products [6]. The Maximum Residue Limit (MRL) is the maximum amount of pesticide which can be present in the food at the time of its sale. These limits are expressed as $\mathrm{mg} / \mathrm{kg}$. These pesticide limits are established by the national governments which ensure that good agricultural practices are being pursued to standardize international trade [7]. These limits are used as indicators of health risks and assure food safety to consumers. Health safety limits for human health are usually expressed as acceptable daily intake ADI. The standard method to calculate human exposure with pesticides is based on the average consumption per person per day, average adult weight, and pesticide residue data [8]. The objective of the study is to provide an analytical method for detecting pesticides in a variety of environmental matrices including fruits, vegetables, water, and soil and also to assess the health risk associated with the presence of pesticides in a wide range of fruits and vegetables.

\section{Materials and Methods}

2.1. Primary Data Collection. Initially, primary data was collected, studied, and revised from selected agricultural areas of Lahore. After the extraction of relevant information, detailed visits were planned. The information gathered from field visits was about the types of fruits and vegetables grown, pesticides used in that area, and reasons and frequency of pesticides used in that area.

2.2. Collection of Samples. Three types of samples were collected from the agricultural areas of Lahore. Fresh fruits and vegetables were acquired from agricultural fields before sending them to the markets. Samples of vegetables, fruits, and soil were obtained in labeled polythene bags and were quickly transported to the laboratory for analysis. The water samples used for irrigation purposes were collected from market Raiwind, badian, and market area in autoclaved bottles. Controlled samples for each vegetable, fruit, soil sample, and wastewater were also collected for the comparative analysis ( $t$ was taken from the farm where no pesticides are used). All samples were kept at room temperature and transported to Kinnaird College's
Environmental Science Laboratory for experimentation. Table 1 shows the sample type and sampling location of different samples.

2.3. Selection of Pesticides. On the basis of primary data, field surveys and interviews with farmers concerning the type, amount, and frequency of pesticides that are sprayed on the sites were conducted. The farmers were found spraying pesticides in selected agricultural sampling areas. The pesticides selected were Glyphosate, Bifenthrin, Amamectin, Imidacloprid, Difenoconazole, Dichlorvos, and Lambda.

\subsection{Experimental Chemical, Apparatus, and Instrumentation.} HPLC grade chemicals, i.e., ethyl acetate, dichloromethane, methanol, sodium chloride, sodium anhydrous sulphate, acetonitrile, and distilled water, were used in the experiment. The main apparatus and equipment used in the experiment were magnetic stirrer, rotary evaporator, and high-performance liquid chromatography (UV-Visible).

2.4.1. Sample Preparation and Pretreatment. The samples of fruits, vegetables, and soil were prepared for the determination of pesticides. The samples were pretreated for running before being analyzed by high-performance liquid chromatography. Fruit and vegetable samples were chopped, air-dried for 4-5 days, and then ground into a fine powder form prior to extraction. Soil samples were also air-dried and crushed into a fine powder.

2.4.2. Preparation of Vegetable and Fruit Samples. $2 \mathrm{~g}$ of airdried and finely ground fruit and vegetable sample was taken in a beaker and mixed with $40 \mathrm{ml}$ of ethyl acetate, $40 \mathrm{ml}$ of dichloromethane (DCM), $150 \mathrm{ml}$ of distilled water, and $5 \mathrm{~g}$ of $\mathrm{NaCI}$ on a magnetic stirrer. This mixture was then transferred to separating funnel and allowed to stand for 30 minutes until two layers were formed. The lower layer (organic layer) was collected in a beaker. $40 \mathrm{ml}$ of ethyl acetate: DCM $(1: 1)$ was added additionally in the upper layer. The lower organic layer when formed was collected and mixed with the previous organic layer. The same extraction process was repeated for all fruit and vegetable samples.

2.4.3. Preparation of Soil Sample. $5 \mathrm{~g}$ of air-dried and finely ground soil sample was taken in a beaker and followed by the addition of $40 \mathrm{ml}$ of dichloromethane (DCM), $40 \mathrm{ml}$ ethyl acetate, and $200 \mathrm{ml}$ of distilled water. The mixture was placed on a magnetic stirrer for 15 minutes to get a homogenous mixture. Then, it was shifted into a separating funnel to allow the separation of the organic layer from the aqueous layer. When both layers got separated, the organic layer was collected in a beaker. $20 \mathrm{ml}$ of ehty 1 acetate and dichloromethane each was added again into the aqueous layer. After 10 minutes, both organic layers were mixed. This extraction procedure was repeated for all soil samples. 
TABLE 1: Mean concentration of detected pesticides.

\begin{tabular}{|c|c|c|c|c|c|c|c|c|}
\hline Samples & $\begin{array}{c}\text { Samples } \\
\text { names }\end{array}$ & $\begin{array}{l}\text { Sample } \\
\text { location }\end{array}$ & $\begin{array}{c}\text { Amamectin } \\
(\mathrm{ppm})\end{array}$ & $\begin{array}{c}\text { Bifenthrin } \\
(\mathrm{ppm})\end{array}$ & $\begin{array}{c}\text { Dichlorvos } \\
(\mathrm{ppm})\end{array}$ & $\begin{array}{c}\text { Glyphosate } \\
(\mathrm{ppm})\end{array}$ & $\begin{array}{c}\text { Imidacloprid } \\
(\mathrm{ppm})\end{array}$ & $\begin{array}{c}\text { Lambda } \\
(\mathrm{ppm})\end{array}$ \\
\hline \multirow{8}{*}{ Fruits } & \multirow{3}{*}{ Grape fruit } & Market & - & - & - & 0.7451 & - & - \\
\hline & & Badian & - & - & - & 6.1576 & - & - \\
\hline & & Market & 2.1247 & 1.3527 & 2.0926 & 0.5082 & - & - \\
\hline & \multirow[t]{2}{*}{ Guava } & Badian & - & - & - & - & - & - \\
\hline & & Raiwind & - & - & - & 0.2576 & 0.0091 & - \\
\hline & \multirow{3}{*}{ Orange } & Market & - & 2.2250 & - & 0.5705 & - & - \\
\hline & & Badian & & - & - & 1.4352 & - & - \\
\hline & & Raiwind & - & - & - & 1.1016 & - & - \\
\hline \multirow{8}{*}{ Soil samples } & \multirow{2}{*}{$\begin{array}{c}\text { Carrot } \\
\text { Grape fruit }\end{array}$} & Badian & - & 0.7289 & - & - & - & - \\
\hline & & Badian & - & 0.2324 & - & - & - & - \\
\hline & \multirow{2}{*}{ Guava } & Badian & - & 28.1500 & - & - & - & - \\
\hline & & Raiwind & - & - & - & - & - & - \\
\hline & \multirow{2}{*}{ Orange } & Badian & - & 0.2057 & - & - & - & - \\
\hline & & Raiwind & - & - & - & - & - & - \\
\hline & Spinach & Badian & - & 0.2443 & - & - & - & - \\
\hline & Turnip & Badian & - & - & - & - & - & - \\
\hline \multirow{6}{*}{ Vegetables } & \multirow{2}{*}{ Carrot } & Market & - & - & - & 0.2892 & - & - \\
\hline & & Badian & - & 13.5772 & - & - & - & - \\
\hline & \multirow{2}{*}{ Spinach } & Market & - & - & - & - & - & - \\
\hline & & Badian & - & 21.6753 & - & - & - & - \\
\hline & \multirow{2}{*}{ Turnip } & Market & - & - & - & 0.9306 & - & - \\
\hline & & Badian & - & - & - & - & 0.0063 & - \\
\hline \multirow{8}{*}{$\begin{array}{l}\text { Water } \\
\text { samples }\end{array}$} & Carrot & Badian & 0.5495 & - & 0.5412 & 0.4593 & - & - \\
\hline & Grape fruit & Badian & 0.4541 & - & 0.4472 & - & 0.0054 & - \\
\hline & \multirow{2}{*}{ Guava } & Badian & 0.3304 & - & 0.3254 & - & - & - \\
\hline & & Raiwind & - & - & - & - & - & - \\
\hline & \multirow{2}{*}{ Orange } & Badian & 14.2435 & - & 14.0286 & - & - & - \\
\hline & & Raiwind & - & - & - & - & - & - \\
\hline & Spinach & Badian & - & - & - & - & - & - \\
\hline & Turnip & Badian & - & 0.4185 & - & - & - & - \\
\hline
\end{tabular}

2.4.4. Preparation of Water Samples. $200 \mathrm{ml}$ of water sample along with $40 \mathrm{ml}$ of ethyl acetate and $40 \mathrm{ml}$ of dichloromethane was taken in a beaker and allowed to mix for 15 minutes on a magnetic stirrer. The mixture of wastewater and organic solvents was then transferred into a separating funnel for 30 minutes and was allowed to separate. The organic layer was taken in a beaker after 30 minutes so that organic layers separate from the aqueous layer. The lower layer which is the organic layer was collected and the upper layer was followed by the addition of $20 \mathrm{ml}$ of ethy1 acetate and $20 \mathrm{ml}$ of DCM again. After 10 minutes of stay, the organic layer was again collected and mixed with the previous organic layer. The same process was repeated for all wastewater samples.

2.4.5. Dehydration. To ensure the removal of any water vapors from the organic layer, 20 gm of sodium sulphate was added in each sample. The mixture was then filtered through Whitman filter paper. The solvent from the mixture was evaporated in a rotary evaporator at $40^{\circ} \mathrm{C}$, and leftover residues were collected by adding $20 \mathrm{ml}$ of methanol. For fruit samples, $10 \mathrm{gm}$ of sodium sulphate was used (Figure 1).

2.4.6. Preparation of Standards. Seven pesticides, i.e., Amamectin, Bifenthrin, Dichlorvos, Glyphosate,
Imidacloprid, Difenoconazole, and Lambda standard stock solution, were prepared by perusing the same procedure as for sample preparation with the only difference in the amount of sample and solvent. For all the standards, $1 \mathrm{mg}$ of the compound was mixed with $30 \mathrm{ml}$ of distilled water and $30 \mathrm{ml}$ of solvents with no addition of $\mathrm{NaCl}$. Then, $5 \mathrm{ml}$ of methanol of HPLC grade was added.

\subsubsection{High-Performance Liquid Chromatography (HPLC)} Analysis. In the prepared samples and standard vials, $15 \mathrm{ml}$ of methanol was added to completely fill the vials. We wash the HPLC vials with distilled water and methanol and fill the prepared samples and standards in HPLC Agilent 1260, Quaternary Gradient System, set at chromatographic conditions.

The solution obtained after extraction and cleanup was diluted by adding $5 \mathrm{ml}$ to $7 \mathrm{ml}$ of methanol in $0.5 \mathrm{ml}$ of sample based on the consistency of the sample and desired color acquired. For dark colored samples, $7 \mathrm{ml}$ of methanol was added, and for light-colored samples, $5 \mathrm{ml}$ of methanol was added; each dilution was injected in the HPLC system equipped with Diode UV/V is detector set at $254 \mathrm{~nm}$. C18 Licospher column was used with an acetonitrile: water (40: 60) mobile phase at a flow rate of $1.0 \mathrm{ml} / \mathrm{min}$ at $25^{\circ} \mathrm{C}$ column temperature. The injection volume was $5.000 \mu \mathrm{l}$. 


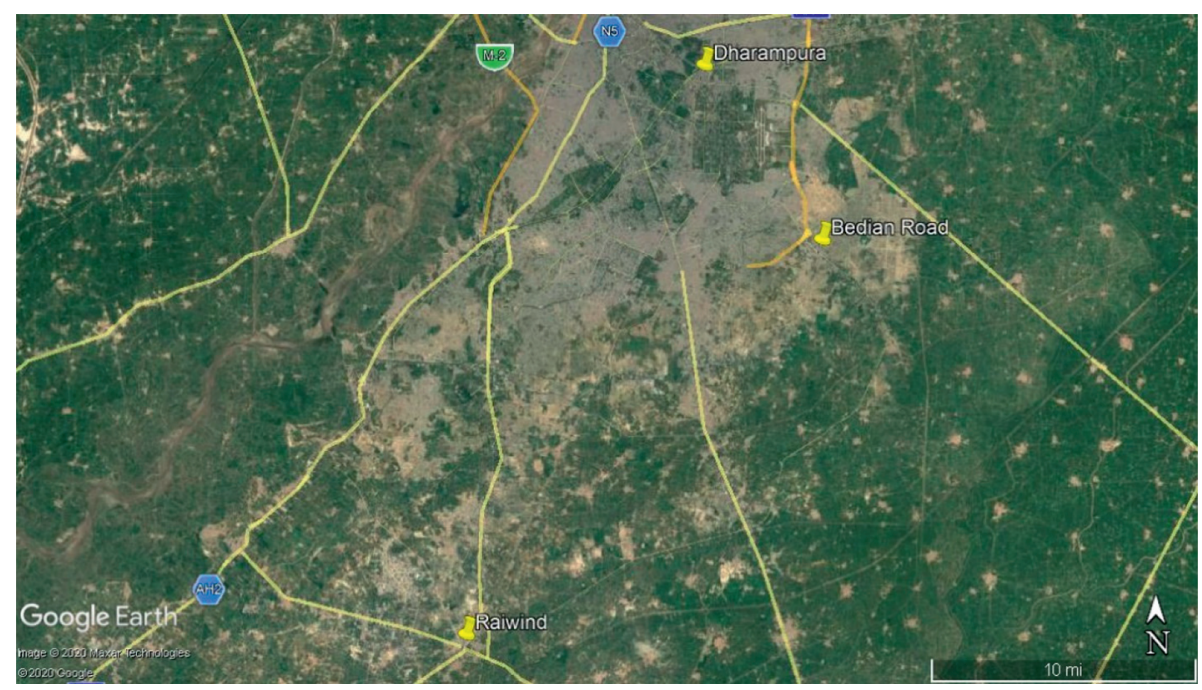

Figure 1: Map of the study area.

2.5. Quality Assurance and Method Validation. Each sample and standard was run in triplicate for quality assurance following the European commission guidelines. For method validation, optimization studies were performed in triplicate on each HPLC parameter like solvent ratio, $\mathrm{pH}$, column temperature, sample/injection volume, flow rate, wavelength and post time, etc. System sensitivity, linearity, and peak area reproducibility were also evaluated. For precision in optimization, only one parameter was changed once keeping all other parameters constant. The recovery of pesticides was determined by spiking with a standard pesticide aqueous solution. For accuracy measurement, the actual spiked values of samples were compared with the samples with known concentrations of respective pesticides. Calibration experiments were tested for linearity, accuracy, and precision. The limit of detection and the limit of quantification were considered as "an individual analytical procedure is the lowest amount of analyte in a sample which can be detected but not necessarily quantified as an exact value" and "an individual analytical procedure is the lowest amount of analyte in a sample which can be quantitatively determined with suitable precision and accuracy." The limit of detection $(3: 1)$ and limit of quantification $(10: 1)$ were calculated as a signal-to-noise ratio. In the current study, LOD was 0.01 while LOQ was $0.03 \mathrm{mg} / \mathrm{L}$, respectively, for the selected pesticides.
2.6. Qualitative and Quantitative Analysis. After the qualitative assessment of the presence of pesticides in each sample, quantitative analysis was carried out to calculate the quantity of detected pesticides. For this purpose, the following formulas formulated by CHROMacademy were used:

$$
\text { response factor }=\frac{\text { peak area of standard }}{\text { standard amount }} \text {. }
$$

The concentration of the analyte in each sample will be calculated by

$$
\text { amount of analyte }=\frac{\text { peak area of sample }}{\text { response factor }} .
$$

2.7. Health Risk Assessment. The degree of risk associated with the consumption of each pesticide detected was monitored by evaluating the results of pesticide residues detected in samples. The health risk index was found by using EDI and ADI. ADI was used from literature studies. The EDI was calculated by multiplying the average consumption of a person per day (kg/day) and residual concentration of pesticide $(\mathrm{mg} / \mathrm{kg})$ and dividing by the average weight of an Asian $(60 \mathrm{~kg})$. The average consumption of fruit and vegetables for adults was considered 0.43 and $0.345 \mathrm{~kg} /$ person/day according to the field survey. The health risk index for each pesticide was calculated using the following formula [9]:

$$
\begin{aligned}
\text { health risk index } & =\frac{\text { estimated daily intake }}{\text { acceptable daily intake }}, \\
\text { EDI } & =\frac{\text { concentration of detected pesticide } x \text { food consumption }}{\text { body weight of an adult }} .
\end{aligned}
$$




\section{Results and Discussion}

The presence of pesticides in samples was confirmed by comparing the standard chromatogram with the sample chromatogram. According to the results obtained, six pesticides were detected in different samples of fruits, vegetables, soil, and water. Detected pesticides were Amamectin, Bifenthrin, Dichlorvos, Glyphosate, Imidacloprid, and Difenoconazole. One of the pesticides Lambda was not detected in any sample.

Amamectin was present in guava samples. The general practice of farmers is to spray the fruit or vegetable with pesticides before sending them to the market to increase its shelf life. However, the pesticides are also absorbed from the soil and water as they were found to be present in samples. The peak of the sample chromatogram is in accordance with the peak of the standard chromatogram. The analysis has also revealed the presence of Amamectin in water samples of orange, guava, grapefruit, and carrot. Among all these, the water which is used for orange contained the maximum amount of Amamectin as compared to all other samples. The reason behind this could be that the water was standing and it also absorbs the pesticides from the soil and its environment. Another possibility is that the water used for irrigation was already toxic and mixed with the pollutants. However, only fruit and water samples had Amamectin but it was not present in vegetable or soil samples. It is dangerous for human health because it can damage the nerve cells of our human body and also affects the muscle cells, so the farmers should be very careful while the application of this pesticide. Glyphosate commonly used as a fungicide and is used to control weeds and/or herbs in agricultural fields. Glyphosate was detected in orange samples. Both samples of grapefruit obtained contained Glyphosate. Two samples of guava also contained the residues of Glyphosate. In vegetable samples, carrot and turnip had the residues. In water samples, only carrot water had the residue of Glyphosate. It was not present in any soil sample. Human health is affected if too much pesticide is used as pesticides are not good for health at all and can cause cancer [10]. Imidacloprid is commonly used as an insecticide to control pests in agricultural fields. The peak was used as the diagnostic peak of Glyphosate in fruit, vegetable, and soil samples. The concentration of Imidacloprid was detected in spinach, bitter gourd, mustard plant, beetroot, guava, and soil samples. The concentration of Imidacloprid in samples was 6.667, 3.374, $1.9643,1.2902,2.392$, and $8.3090 \mathrm{mg} / \mathrm{kg}$, respectively. The permissible limit of Imidacloprid for beetroot is $0.5 \mathrm{mg} / \mathrm{kg}$. This pesticide was also present in one water sample of grapefruit. It is known as persistent in nature and persists in soil. Health effects associated with its consumption include neurotoxicity, reproductive, and mutagenic health effects [11].

Another pesticide whose concentration was detected in samples was Difenoconazole. It is used as a fungicide for disease control in fruits, vegetables, and crops. It is a broadspectrum nitrogen-containing fungicide that belongs to the group of triazole [12]. Difenoconazole was detected in two fruit samples, i.e., orange and guava, and one vegetable sample, mustard plant. The concentration of Difenoconazole in oranges, guavas, and lemons was $3.4680 \mathrm{mg} / \mathrm{kg}$, $12.264 \mathrm{mg} / \mathrm{kg}$, and $433.162 \mathrm{mg} / \mathrm{kg}$, respectively. The permissible limits prescribed by the MRLs for orange and guava and lemon are $0.6 \mathrm{mg} / \mathrm{kg}, 0.8 \mathrm{mg} / \mathrm{kg}$, and $0.8 \mathrm{mg} / \mathrm{kg}$, respectively. The residual concentration of Difenoconazole in oranges and guavas was 578 and 1533 times higher than the permissible limit. The concentration of Difenoconazole in the mustard plant was $15.2899 \mathrm{mg} / \mathrm{kg}$. The permissible limit for the mustard plant according to MRLs was $2 \mathrm{mg} / \mathrm{kg}$. The residual amount of Difenoconazole in the mustard plant was 794 times higher than the permissible limits. The concentration of Difenoconazole in soil was $23.0855 \mathrm{mg} / \mathrm{kg}$. However, the MRLs for the concentration of Difenoconazole in soil samples are not available. Difenoconazole is known for its high persistence in the soil. Hence, the residual amount of Difenoconazole in fruit and vegetable samples is associated with their high persistence in soil. Consumption of foods containing Difenoconazole above the permissible limits can cause serious health implications including carcinogenicity, decreased human fertility, and neurotoxicity, reproductive, developmental, and acute toxicity [13] Bifenthrin is a pyrethroid compound used as an effective pesticide used for agricultural fields, fruits, and vegetable pest control. However, the peaks of a few samples of fruits, vegetables, soil, and water were similar to those of standard peaks of Bifenthrin. The results reveal that fruits like oranges and guavas contained Bifenthrin. The concentrations in oranges and guavas collected from different areas were $2.225 \mathrm{mg} / \mathrm{kg}, 1.452 \mathrm{mg} / \mathrm{kg}, 4.475 \mathrm{mg} / \mathrm{kg}$, and $3.37749 \mathrm{mg} / \mathrm{kg}$, respectively. The standard limits of this insecticide according to MRLs in oranges and guavas are 0.05 and $0.03 \mathrm{mg} / \mathrm{kg}$, respectively. The concentration of Bifenthrin in both fruit samples was higher in comparison with WTO and MRLS. Vegetables especially carrots, mustard plants, and spinach collected from different sources had the highest levels of Bifenthrin as it was $13.57 \mathrm{mg} / \mathrm{kg}, 1.7612 \mathrm{mg} / \mathrm{kg}$, and $21.67 \mathrm{mg} / \mathrm{kg}$, respectively. In soil samples, orange and guava soil samples did not have any residue of Bifenthrin. Both samples of guavas and oranges were exceeding the Maximum Residue Limits (MRLs). They were much higher than the permissible level. However, the soil samples of grapefruits, oranges, guavas, carrots, and spinach all contained the residues of Bifenthrin. Among all guavas, the soil had the maximum residue up to $28.15 \mathrm{mg} / \mathrm{kg}$ which is very high. Only one sample of water of turnip had some residue of Bifenthrin. The reason for its presence in fruits, vegetables, and the soil is due to its ability of bioaccumulation and high persistence in environmental matrices. Long persistency of Bifenthrin under aerobic and anaerobic conditions has been observed by many researchers. The degradation rate of Bifenthrin in the soil is very much slower due to its half-life which varies from 8 to 17 months at $20^{\circ} \mathrm{C}$ [14]. It is transported to fruits and vegetables through contaminated soil; due to its high toxicity and adverse health impacts, it is banned in various countries. It is dangerous for human health as it belongs to the pyrethroid family. Health implications linked with the exposure to Bifenthrin include irritation, headache, dizziness, nausea, allergies, asthma, 
TABLE 2: Health risk assessment of pesticide residues in sample fruits and vegetables.

\begin{tabular}{|c|c|c|c|c|c|c|}
\hline Sample type & Type of pesticides & ADI $(\mathrm{mg} / \mathrm{kg} / \mathrm{d})$ & EDI $(\mathrm{mg} / \mathrm{kg} / \mathrm{d})$ & Sample name & HRI & Health risk \\
\hline \multirow{10}{*}{ Vegetable samples } & \multirow{3}{*}{ Bifenthrin } & \multirow{3}{*}{0.01} & \multirow{3}{*}{0.45} & Spinach 1 & 7.8 & Yes \\
\hline & & & & Carrot & 12.46 & Yes \\
\hline & & & & Spinach 2 & 1.01269 & Yes \\
\hline & \multirow{5}{*}{ Imidacloprid } & \multirow{5}{*}{0.06} & \multirow{5}{*}{0.45} & Mustard plant & 0.1881 & No \\
\hline & & & & Spinach 1 & 0.6389 & No \\
\hline & & & & Beet root & 0.1236 & No \\
\hline & & & & Bitter gourd & 0.3233 & No \\
\hline & & & & Turnip & 0.891 & No \\
\hline & \multirow{2}{*}{$\begin{array}{c}\text { Difenoconazole } \\
\text { Glyphosate }\end{array}$} & \multirow{2}{*}{$\begin{array}{c}0.01 \\
0.3\end{array}$} & \multirow{2}{*}{$\begin{array}{l}0.45 \\
0.45\end{array}$} & Mustard plant & 8.7916 & Yes \\
\hline & & & & Carrot & 0.0055 & No \\
\hline \multirow{14}{*}{ Fruit samples } & \multirow{4}{*}{ Bifenthrin } & \multirow{4}{*}{0.01} & \multirow{4}{*}{0.43} & Orange 1 & 1.594 & Yes \\
\hline & & & & Guava 1 & 0.96 & No \\
\hline & & & & Orange 2 & 3.2 & Yes \\
\hline & & & & Guava 2 & 2.704 & Yes \\
\hline & \multirow{2}{*}{ Imidacloprid } & \multirow{2}{*}{0.06} & \multirow{2}{*}{0.43} & Guava 1 & 0.001 & No \\
\hline & & & & Guava 2 & 0.285 & No \\
\hline & \multirow{2}{*}{ Difenoconazole } & \multirow{2}{*}{0.01} & \multirow{2}{*}{0.43} & Orange & 2.485 & Yes \\
\hline & & & & Guava & 8.789 & Yes \\
\hline & \multirow[t]{3}{*}{ Amamectin } & \multirow[t]{3}{*}{0.0005} & \multirow[t]{3}{*}{0.43} & Guava & 30.454 & Yes \\
\hline & & & & Grapefruit & 0.0177 & No \\
\hline & & & & Guava 1 & 0.0121 & No \\
\hline & \multirow[t]{3}{*}{ Glyphosate } & \multirow[t]{3}{*}{0.3} & \multirow[t]{3}{*}{0.43} & Orange 1 & 0.0136 & No \\
\hline & & & & Orange 2 & 0.0342 & No \\
\hline & & & & Orange 3 & 0.2427 & No \\
\hline
\end{tabular}

nasal discharge, bronchitis, sinusitis, and sneezing. It affects the nervous system of a human being. It is also carcinogenic in the long run [15]. Dichlorvos belongs to the organophosphate group; it was detected only in one sample of fruit, i.e., guavas. Other than that, it was present in most of the water samples, i.e., orange, guava, grapefruit, and carrot water. Canal water is used for irrigation and there is a possibility that it is contaminated with the industrial effluents. It also affects the nervous system and inhibits the choline esterase enzymes in the nervous system. Long-term exposure can cause endocrine disruption and weaken the immune system. Short-term exposure will cause headaches, fatigue, loss of memory, and convulsions.

3.1. Risk Assessment. To estimate the degree of risk which can be caused by the detected pesticide residues in samples, an exposure analysis was carried out by monitoring the results. Risk assessment was calculated by using EDI and ADI. EDI was calculated by average consumption per person per day and pesticide residue data. The percent EDI to ADI ratio was calculated by multiplying it with the average body weight of $60 \mathrm{~kg}$ [8]. The EDI for vegetables and fruits was 0.45 and 0.43 , respectively. Hazard index for Difenoconazole in mustard plants, oranges, and guavas was 8.7916, 2.485, and 8.789, respectively. Hazard index for Bifenthrin in spinach, carrots, oranges, and guavas was 7.8, 12.46, 3.2, and 2.704, respectively. The hazard index for Amamectin in guavas was 30.454 . In all of the above three pesticides (Difenoconazole, Bifenthrin, and Glyphosate), health risk was high. Results exceeding the cut-off value of 1 indicate the potential health risk. Pesticides like Imidacloprid and
Glyphosate had no potential health risk due to the values below the cut-off limit of 1 . The results indicate that even in some samples the pesticide residual concentration was exceeding the maximum residual levels but had no associated health risks (Table 2 ).

\section{Conclusions and Recommendations}

The use of pesticides has greatly enhanced agricultural production. But this is only one side of the coin; the other side showed that the presence of these pesticides has resulted in serious threats to human health and the environment. This study reveals the presence of pesticides in fruits and vegetables exceeding the MRLs. Pesticides such as Bifenthrin, Amamectin, and Difenoconazole pose significant health risk toward consumers as their health risk indices were above the cut-off value of 1 . The results reveal the health risk indices of Bifenthrin and Difenoconazole ranging from 7.8 to 12.46 in vegetables and from 2.704 to 30.454 in fruits, hence, posing a serious threat to human health. In developing countries like Pakistan, some legal measures should be taken in order to monitor the pesticide residues in fruits and vegetables because of potential health risks and to accomplish the standards and to make the products safely consumable by the consumers. It is also recommended that in future studies the risk for child and expecting mothers can be calculated.

\section{Data Availability}

The data used to support the findings of this study are available from the corresponding author upon request. 


\section{Conflicts of Interest}

The authors declare that they have no conflicts of interest.

\section{References}

[1] Pakistan Bureau of Statistics, 2019, http://www.pbs.gov.pk/ sites/default/files//tables/Table-7_0.pdf.

[2] J. L. F. Moreno, F. J. A. Libanas, A. G. Frenich, and J. L. M. Vidal, "Evaluation of different sample treatments for determining pesticide residues in fat vegetable matrices like avocado by low pressure gas chromatography-tandem mass spectrometry," Journal of Chromatography A, vol. 1111, no. 1, pp. 97-105, 2006.

[3] W. L. Claeys, J.-F. Schmit, C. Bragard, G. Maghuin-Rogister, L. Pussemier, and B. Schiffers, "Exposure of several Belgian consumer groups to pesticide residues through fresh fruit and vegetable consumption," Food Control, vol. 22, no. 3-4, pp. 508-516, 2011.

[4] C. K. Schiffers, A. B. Kwofie, D. Denutsui, J. Asomaning, and A. O. Tutu, "Monitoring of pesticide residues in fruits and vegetables and related health risk assessment in kumasi metropolis, Ghana," Research Journal of Environmental and Earth Sciences, vol. 3, no. 6, pp. 761-771, 2011.

[5] J. Gan, S. J. Lee, W. P. Liu, D. L. Haver, and J. N. Kabashima, "Distribution and persistence of pyrethroids in runoff sediments," Journal of Environmental Quality, vol. 34, no. 3, pp. 836-841, 2005.

[6] A. Sana, Y. Ghazala, H. Almas, A. Zainab, and A. Sidra, "Determination of pesticide residues in selected vegetables and fruits from a local market of Lahore," Current World Environment, vol. 13, no. 2, pp. 242-250, 2018.

[7] A. Z. Chowdhury, M. Hasan, N. Karim et al., "Contamination and health risk assessment of pesticide residues in vegetables from agricultural fields of gazipur district, Bangladesh," Journal of Agriculture \& Environmental Science, vol. 14, no. 5, pp. 421-427, 2014.

[8] Y.-H. Seo, T.-H. Cho, C.-K. Hong et al., "Monitoring and risk assessment of pesticide residues in commercially dried vegetables," Prevention Nutrition and Food Science, vol. 18, no. 2, pp. 145-149, 2013.

[9] M. S. Hossain, A. N. M. Fakhruddin, A. Z. M. Chowdhury, M. A. Rahman, and A. M. Khorshed, "Health risk assessment of selected pesticide residues in locally produced vegetables of Bangladesh," International Food Research Journal, vol. 22, no. 1, pp. 110-115, 2015.

[10] Y. Latif, S. T. H. Sherazi, and M. I. Bhanger, "Monitoring of pesticide residues in commonly used fruits in hyderabad region, Pakistan," American Journal of Analytical Chemistry, vol. 2 , no. 8, pp. 46-52, 2011.

[11] L. Chensheng, K. Toepel, R. Irish, R. A. Fenske, D. B. Barr, and R. Bravo, “Organic diets significantly lower children's dietry exposure to organophosphorus pesticides," Environmental Health Perspectives, vol. 114, no. 2, pp. 260-263, 2006.

[12] Y.-F. Jiang, X.-T. Wang, Y. Jia et al., "Occurrence, distribution and possible sources of organochlorine pesticides in agricultural soil of Shanghai, China," Journal of Hazardous Materials, vol. 170, no. 2-3, pp. 989-997, 2009.

[13] S. Tao, W. Liu, Y. Li et al., "Organochlorine pesticides contaminated surface soil as reemission source in the haihe plain, China," Journal of Environmental Science and Technology, vol. 42, no. 22, pp. 8395-8400, 2004.

[14] H.-Y. Zhang, R.-T. Gao, Y.-F. Huang, X.-H. Jia, and S.-R. Jiang, "Spatial variability of organochlorine pesticides
(DDTs and HCHs) in surface soils from the alluvial region of Beijing, China," Journal of Environmental Sciences, vol. 19, no. 2, pp. 194-199, 2007.

[15] Z. R. Parveen, S. Iqbal, B. M. Abbas, and M. Ahmed, "Monitoring of multiple pesticides residues in some fruits in Karachi, Pakistan," Pakistan Journal of Botany, vol. 43, no. 4, pp. 1915-1918, 2011. 